\title{
Experimental techniques in high temperature thermodynamics
}

\author{
Kurt L. Komarek \\ Institute of Inorganic Chemistry, University of Vienna, Währingerstraße 42 , \\ A-1090 Vienna, Austria
}

\begin{abstract}
An overview of the most recent developments of experimental techniques used in high temperature thermodynamics will be given. Calorimetric, EMF, and vapor pressure methods will be discussed with special emphasis on solid electrolyte galvanic cell techniques and Knudsen effusion mass spectrometry.

The essential criteria for the satisfactory application of solid electrolyte galvanic cell methods will be presented and the principal electrolytes presently in use will be surveyed. Special variations of the cell technique used in thermodynamic studies are described.

With respect to vapor pressure methods the focus will be on the fundamentals of the Knudesen effusion mass spectrometry. Recent methodic developments were less due to radically new techniques but more to automated control, data acquisition and processing.
\end{abstract}

\section{INTRODUCTION}

The definition of high temperature science has occupied many of the attendees of this conference in many a Conference of High Temperatures. Leo Brewer's definition is a classic one: "... when things start behaving the way you don't expect them to behave", yet this implies that there is no such fixed temperature boundary and it really depends on the field you are working in. Since my field is thermodynamics of inorganic metallic systems and thermodynamics does depend on the establishment of equilibrium, experimental techniques used for such measurements will - roughly speaking - be confined to the temperature regimen above $1000 \mathrm{~K}$. In previous publications the author has quite extensively discussed experimental techniques applied in high temperature thermodynamics and phase diagram studies (Ref.1-5). Since then other general (e.g. Ref.6,7) or more special (e,g. Ref,8,9) publications have appeared which have treated the same subjects. This review will obviously also incorporate material that has been covered in those and other articles. Needless to say that this review is selective and not exhaustive.

\section{CALORIMETRIC METHODS}

For a high temperature chemist both thermophysical and thermochemical data are important. Therefore the calorimetry of non-reacting systems cannot be separated from that of reacting systems. Besides as far as results are concerned the methods overlap since valuable information on excess molar heat capacities can be obtained from careful measurements of the enthalpy of mixing of liquid alloys at various temperatures (e.g. Ref.10) or vice versa, excess molar heat capacities can be derived from heat capacity measurements on pure elements and alloys.

Non-reacting calorimetry attempts to determine heat capacities, enthalpies of transformation, and heat contents. The most accurate results for heat capacities are obtained by adiabatic calorimetry, both at low (i.e. below room temperature) and at high temperatures. Low temperature work requires special experimental techniques, and frequently results between the two temperature regimens do not match. An exception is the unsurpassed agreement between the low-temperature $C_{p}$ data of Westrum and the high temperature $C_{p}$ results of Gronvold (e.g. Ref.11,12). For high-temperature $C_{p}$ measurements the adiabatic calorimeters (temperature range $800-1800 \mathrm{~K}$ ) of Rogez and Le Coze (Ref.13) and (temperature range $700-1700 \mathrm{~K}$ ) of Kubaschewski and Grundmann 
(Ref.14) should be mentioned. At very high temperatures pulse heating methods of wireor tube-shaped specimens are employed (e.g. Ref.15-17).

Heat contents at higher temperatures are in most cases determined by drop calorimetry using either heat flow, isoperibol or isothermal calorimeters. Special attention must be paid to heat losses during the drop and to non-equilibrium states due to rapid cooling. Such problems can be avoided by drop calorimetry from room to high temperatures (so-called "reverse drop calorimetry") using high temperature calorimeters (e.g. Ref.18,19). Heating by levitation in combination with an isoperibol copper block calorimeter has been used by Frohberg and coworkers to measure heat contents of molybdenum (Ref.20), niobium (Ref.21) tantalum (Ref.22), tungsten (Ref.23) and vanadium (Ref.24) up to $3000 \mathrm{~K}$. Above this temperature heat losses due to thermal radiation increase drastically. The brightness temperatures were measured optically and the true temperature of the sample calculated by means of the spectral emissivity of the refractory metals. Convection and radiation heat losses during the drop were evaluated (Ref.25).

In a recent article Castanet (Ref.26) described the various calorimetric methods of reacting systems and distinguished direct reaction calorimetry, solution calorimetry, precipitation and combustion calorimetry. For high temperature work the most popular calorimeters are of the heat flow type. The most convenient procedure is the direct drop method: pure solid $A$ is dropped from room temperature into the calorimeter containing the liquid sample (pure B or alloy AxBy). When the heat content of $A$ is not well known or the enthalpy of mixing is positive the indirect drop method is preferable preheating A before the drop (e.g. Ref.27,28). A calorimeter for the determination of enthalpies of mixing up to temperatures of $2000 \mathrm{~K}$ was constructed by Lück and Predel (Ref.29). The metal A (to be added to metal B in the calorimeter block with stirrer) is preheated in a charge crucible with stopper to be opened when thermal equilibrium is reached. Bros (Ref.30) described two calorimeters used in many investigations of binary and ternary systems: a) The typical Calvet microcalorimeter operating between 500 - $1100 \mathrm{~K}$ with cells (laboratory and reference cell) both side by side in a central block, each surrounded by a thermopile connected differentially to eliminate thermal perturbations caused by the furnace. b) A high temperature calorimeter (operating range 1100 - $1800 \mathrm{~K}$ ) with laboratory cell above and reference cell below with the thermocouple pile detector arranged vertically around the two crucibles. Both the direct and the indirect drop method can be used. Kleppa and coworkers have modified a Setaram-type heat flow calorimeter to operate at $1473 \mathrm{~K}$ (Ref $31,32)$ and have measured standard enthalpies of formation of various transition metal germanides (Ref.32-34). In the solute-solvent drop method a weighed amount of a third metal was added to form a liquid ternary alloy when the melting point of the binary germanide was very high above the operating temperature of the calorimeter. With reasonably low melting compounds the direct synthesis method was used, i.e. elements and compounds, resp., were dropped into the calorimeter without the addition of a third metal. Gachon and Hertz (Ref.35-39) have also applied the direct synthesis method to determine the enthalpy of formation of a series of transition metal compounds at $1800 \mathrm{~K}$ with a Setaram high temperature calorimeter (Ref.40). Incomplete reaction is the main source of error but with proper attention the results seem to be quite reliable. Arpaci and Frohberg (Ref.41) determined the heat of mixing of liquid molybdenum - silicon alloys at $3000 \mathrm{~K}$ by levitation calorimetry. Although side reactions are eliminated by this method, other sources of error are not so easy to control and estimate. Yet at such high temperatures there is not other method available to measure enthalpies of mixing. A heat flow microcalorimeter was also successfully employed by Gerdanian and coworkers (Ref.42) to measure the partial enthalpies of oxygen in non-stoichiometric oxides.

The use of liquid metallic solvents in solution calorimetry to measure enthalpies of formation has now a history of nearly 40 years when Ticknor and Bever (Ref.43) first dissolved $A g-A u$ alloys in a tin bath. The time of dissolution should be short, the heat effects moderate, and the vapor pressure of the solvent low. Although tin has been a favorite solvent, many other metals have been used like aluminum, copper and copper alloys, nickel and iron (see Ref.1) gallium (Ref.44), and lead (Ref.45). Topor and Kleppa generated the solvents in situ by dropping Pt and LaB6 (Ref.46) and Pt or $\mathrm{Pd}+\mathrm{B}$ and the diborides of $\mathrm{Sc}, \mathrm{Ti}$, and $\mathrm{V}$ (Ref.47) to give a liquid alloy.

In precipitation calorimetry one component is dissolved in the solvent; on addition of the second component a solid compound is formed and precipitates provided its solubility is low enough. First used by Bryant and Pratt (Ref.48) it has been applied by Notin et al (Ref.49) to the compound $\mathrm{Al}_{2} \mathrm{Ca}$. 
The main intention of the calorimetry of reacting systems will be the measurement of enthalpies of formation of compounds and of enthalpies of mixing of solid and liquid alloys. Especially in the latter case the enthalpy of mixing might exhibit a considerable temperature dependence as exemplified by the In-Te system (Ref.50). Neglect of this possibility might lead to erroneous extrapolations when measurements were carried out at temperatures high above the liquidus curve. On the other hand temperature dependent enthalpies of mixing will mean excess heat capacities which in turn are indicative of chemical short range order in the system (Ref.51).

\section{EMF METHODS}

Theoretically the measurement of the emf of a suitable galvanic cell is one of the most accurate methods to obtain thermodynamic properties of alloys. In high temperature thermodynamic studies both liquid and solid electrolytes are used with a shift towards the latter in recent years. The enf technique with fused salt electrolytes has been described in extenso by Moser (Ref.52). An emf cell will yield correct results if it operates reversibly, i.e. if it does not show drift or polarization effects. The emf (at constant temperature) should be independent of time, and it has to be reproducible regardless whether one approaches it from higher or lower temperatures. The emf should be measured in the compensated state, and the same value should be reached when passing a small current from the one or from the other direction. Conduction should be purely ionic, the charge of the more electropositive ion $A^{2+}$ has to be known exactly, $A \rightleftharpoons A^{2+}+Z^{-}$should be the only reaction at the electrode surface, and no displacement reactions should occur. Temperature gradients should be negligible to minimize thermoelectric voltage, and the latter should be determined in a separate experiment, especially when using electrode lead wires of different materials. Concentration changes due to the vapor pressure of electrodes and electrolyte have to be taken into account, reactions between construction materials, and electrodes and electrolyte have to be absent; the furnace should be wound noninductively. Displacement reactions can be either taken into account by careful experimentation and calculation (Ref.53) or by the so-called "Touch Instant Electromotive Force (TIE) Method" of Okajima and Sakao (Ref.54,55). This method and its application to various liquid alloy systems has been exhaustively described quite recently by Okajima (Ref.56). The TIE method is based on the idea of measuring the emf prior to the development of the nonreversible contribution by the displacement reaction in the cell, i.e. by measuring the emf with an oscilloscope at the moment the elctrolyte comes in touch with both electrodes. In principle this allows the determination - in two separate cells - of the activities of both the more and the less electropositive metal of an alloy. No novel aspects or important improvements of emf techniques with liquid electrolytes have been reported in recent years so that this method can be considered as a routine technique.

With the increase in reliability of solid electrolytes their use has steadily increased. Various aspects of solid electrolytes like the theory, the structure of halogenide and oxide electrolytes, $\beta$-aluminas, and mixed ionic-electronic conductors are described in a book edited by Geller (Ref.57), solid electrolytes and their applications in a book edited by Subbarao (Ref.58) and recent developments in oxygen ion conducting solid electrolyte and electrode materials by Burggraaf et al (Ref.58a). Recent review articles treating the application of solid electrolytes in thermodynamic studies are those by Schaller (Ref.59), Egan (Ref.60), and Pratt (Ref.8). The basic requirements for solid electrolytes are thermal stability, ionic conduction and a conductivity of not less than approximately $10^{-6} \mathrm{ohm}^{-1} \mathrm{~cm}^{-1}$. The major electrolytes are calcia-or yttria-stabilized zirconia, yttria- or lanthania-doped thoria, fluorides (especially $\mathrm{CaF}_{2}$ ), and $\beta-$ and $\beta$ - aluminas. The most frequently used electrolytes are those based on zirconia or thoria. They can be either employed as pellets, crucibles, or closed tubes which will assist electrode containment and isolation. Condensed state (metal/metal oxide) or controlled gaseous atmosphere (e.g. Pt/air of Pt/oxygen) reference electrodes can be used. In the latter case the working and reference electrodes and their atmospheres have to be completely separated by an electrolyte tube.

In a carefully evaluated international study of calcia- and yttria-stabilized zirconia tubes recommendations for their use as oxygen gauges were formulated (Ref.61). As the principal sources of error the following factors were cited: 1) Physical permeability of the ceramic materials due to microcracks or open porosity. Because of poor thermal shock resistance zirconia tubes should not be cooled faster than $150 \mathrm{~K} / \mathrm{h}$. 2) Uncertainty in cell temperature, cell voltage, and evaluation of the reference partial 
pressure of oxygen. 3) Nonuniform cell temperature causing thermoelectric voltage and uncertainty in the cell temperature. 4) Small electronic contribution. The flow of electrons is counterbalanced by a small ionic current which induces electrochemical permeability of the material to oxygen. This will inject gas into the gas stream with the smaller partial pressure of oxygen but the diffusive process may also polarize the measuring electrode, and the measured voltage is lowered by the electrode overpotential. Since zirconia cells behave as moderate to high impedance voltage sources, the voltage delivered must be measured with a voltmeter of high internal impedance; gauge and external leads have to be shielded to reduce electrical (capacitance) pick-up. With a carefully constructed gauge the compounded error was less than $0,3 \%$. When measurements at much lower partial pressure of oxygen are made, electronic contributions may play a significant role, and problems in design are greatly increased. Other reference elctrodes have to be used which might lead to the formation of reaction layers at the electrolyte interface, besides a considerable uncertainty might be introduced due to the lack of standardization of the free energy of formation of the reference electrode reaction.

In principle, a galvanic cell can be operated outside the range of purely ionic conduction if the transference number is precisely known.. A theoretical treatment of this problem is based on the analysis of mixed electronic and ionic conduction by Schmalzried (Ref,62,63). However, in galvanic cells with solid coexistence electrodes the flow of electrons and holes, resp., will generate erratic emf data. With electrons migrating from cathode to anode, i.e. with any short circuiting current through the electrolyte, the conditions of local charge and charge flux neutrality throughout the electrolyte require that equivalent amounts of oxygen ions are transported in the opposite direction. If oxygen cannot be removed or supplied rapidly enough by diffusion at the electrode-electrolyte interface, oxide will be formed at the cathode and metal at the anode which gives rise to unstable emf's. Even without layer formation the oxygen transfer due to an electronic current can cause steady-state oxygen gradients in the electrodes, and a stable emf is obtained which includes an overvoltage contribution. Because of these problems solid oxide electrolytes are usually unsuitable to use when the electronic conductivity exceeds a limit of about $1 \%$ of the ionic contribution. It is therefore important to know the temperature and oxygen partial pressure region over which the electronic conductivity is below this level for each electrolyte applied.

For calcia-and yttria-stabilized zirconia the operating oxygen partial pressure range extends from $10^{-18}$ bar to $10^{5}$ bar at $1000^{\circ} \mathrm{C}$ (Ref.64). At partial pressures of oxygen above $10^{5}$ bar and below $10^{-18}$ bar p-type and n-type electronic conductivity, resp., will exceed 1\%. With yttria- or lanthania-doped thoria the range of applicability can be extended to $10^{-25}$ bar at $1000^{\circ} \mathrm{C}$ under reducing conditions (Ref.65) with some evidence that the electrolytic domain might extend to values as low as $10^{-34}$ bar. At high partial pressures of oxygen thoria-based electrolytes are useful up to 10-6 bar at $1000^{\circ} \mathrm{C}$. However, the electrolytic properties of zirconia and in particular of thoria are strongly influenced by impurity content and sample preparation. With thoria-based electrolytes even activities of metals like aluminum, zirconium, or thorium with highly negative enthalpies of formation of their oxides can be measured provided the activities are very small (Ref. 59). Control of the gas atmosphere is very important, and argon as purging gas has to be rigorously purified. Since the partial pressures of oxygen of both electrodes is very different it is sometimes recommended not to keep the cell in a common gas atmosphere but to separate the electrodes by using an electrolyte tube and equilibrating the two gas streams with the metal-metal oxide used as electrode material. However, if the dissociation pressures of the oxides are sufficiently low a common gaseous atmosphere has apparently no influence on the measurements (Ref.59).

The use of fluoride-based electrolytes has been recently discussed by Pratt (Ref.8), Schaller (Ref.59), and Egan (Ref.60). Fluoride electrolytes are especially useful under reducing conditions where solid oxide electrolytes become electronic conductors. They therefore offer the possibility to determine the activity of strongly electropositive metals such as $\mathrm{U}, \mathrm{Th}, \mathrm{Na}$ and $\mathrm{Mg}$. The electrolytic behaviour of $\mathrm{CaF2-}$ the most commonly used fluoride electrolyte-has been investigated by Wagner (Ref.66), Hinze and Patterson (Ref.67), and Egan (Ref.60,68). Wagner estimated that tion) 0.99 for aca $\leq 10^{-5}$ at $873 \mathrm{~K}$ and aca $\leq 6 \cdot 10^{-6}$ at $1113 \mathrm{~K}$, in close agreement with the results of Egan who concluded that in the temperature region of $1073 \mathrm{~K}$ electronic contribution to conductivity can be neglected for aca $\leq 10^{-3}$ which corresponds to a fluorine pressure of 2.10-48 bar. However, Egan (Ref,60) has shown with liquid Ca-Zn alloys that reliable thermodynamic activities can be obtained even if the electrolyte is a 
partial electronic conductor and tion is exactly known. The most serious problem with $\mathrm{CaF}_{2}$ as an electrolyte is its high chemical activity at elevated temperatures. It can easily oxidize and hydrolyze, and purification and drying of the protective atmopheres is necessary to prevent impairment of the ionic conduction. CaFr can form intermediate compounds with other metal fluorides, and side reactions with electrode material might affect the ionic domain. With polycrystalline electrolytes grain boundary diffusion of electrode cations tends to limit cell lifetimes. Therefore it is advantageous to use dense, optical quality, high purity CaF2 single crystals, often in the form of polished plates. For further details of theory and experiment publications of Levitskii (Ref.69) and Kleykamp (Ref.70) should be consulted. Other ionic conducting fluorides such as $\mathrm{SrF}_{2}, \mathrm{MgF}_{2}, \mathrm{BaF}_{2}$, and $\mathrm{PbF}_{2}$ have been used as electrolytes, and Schaller (Ref.59) has reported results in the Pd-Ce system with single- crystal CeF3 as electrolyte which exhibits pure ionic conductivity up to ace $=1$ and is a much better conductor than $\mathrm{CaF}_{2}$.

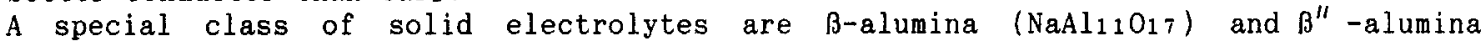
(NaAl508) with a layer structure. The latter has a higher conductivity but in both cases mobility is confined to two-dimensional planes so that polycrystalline material must be used to give three-dimensional conduction. In recent years many liquid sodium alloys have been investigated with $\beta^{\prime \prime}$-alumina as electrolyte such as $\mathrm{Na}-\mathrm{Pb}$ (Ref.71) and $\mathrm{Na}-\mathrm{Hg}$ (Ref.72). An interesting property of these materials is their ability to exchange the $\mathrm{Na}^{+}$ions in the conduction layers for other cations so that a wide range of ionic conductors with different types of cationic species will result. Such exchanges have been made with monovalent ions like $\mathrm{Ag}^{+}, \mathrm{Li}^{+}, \mathrm{K}^{+}, \mathrm{Rb}^{+}, \mathrm{Cs}^{+}, \mathrm{Tl}^{+}, \mathrm{Cu}^{+}$ and $\mathrm{In}^{+}$(Ref.73), with divalent ions such as $\mathrm{Ca}^{2+}, \mathrm{Zn}^{2+}, \mathrm{Cd}^{2+}, \mathrm{Mn}^{2+}, \mathrm{Fe}^{2+}, \mathrm{Ni}^{2+}, \mathrm{and}^{+}$ $\mathrm{Co}^{2+}$ (Ref.74), and trivalent ions like $\mathrm{Bi}^{3+} \mathrm{Cr}^{3+}$ and most rare earth ions (Ref.75). Usually such samples are prepared by exposing the $\beta$-aluminas to solid, liquid or vapor of the halides or nitrates of the substituting cation at elevated temperatures. Complications arise where several oxidation states exist or reduction to metal is easy. Structural stability is a problem, and complete, i.e. 100\% exchange is not always attainable. Application to systems other than Na-alloys has been very limited (Ref.8).

A well established and widely used variation is the coulometric method by which the compositions of the laboratory electrode can be changed and very accurately controlled. It is especially useful in studying the change of thermodynamic properties (activities) in small steps in dilute solutions or in nonstoichiometric compounds. The electrolyte has to be a pure ionic conductor and the electroactive species must have a high diffusion coefficient. However, Egan (Ref.60) has applied coulometry to the Au-Ca system with slower diffusion coefficients by using thin film electrodes (and a CaF2 electrolyte). The coulometric method has been reviewed by Wagner (Ref.76) and has beers used in studies of chalcogenides, of oxygen in liquid alloys, and of solid and liquid systems involving reactive metals. Some noteworthy examples are the thermodynamic investigation of nonstoichiometric $\mathrm{UO}_{2-\mathrm{x}}$ by Nakamura and Fujino (Ref.77) with a stabilized zirconia electrolyte and a $\mathrm{Ni} / \mathrm{NiO}$ reference electrode which also served as an oxygen source, the use of $\beta$-alumina electrolytes for the coulometric study of liquid Na-alloys by Saboungi and Corbin (Ref.78), and the determination of the thermodynamic properties of liquid $\mathrm{Na}-\mathrm{NaBr}$ mixtures with a $\mathrm{CaF}_{2}$-electrolyte by Egan and Freyland (Ref.79).

The so-called "pin-point electrode" method has been first described by Lefebvre et al (Ref.80). A solid electrolyte plate $\left(\mathrm{CaF}_{2}+\mathrm{CaO}\right)$ is on one side in contact with a metal/metal oxide reference electrode and on the other side with three metallic "pinpoint electrodes": an inert reference electrode "a" (Fe), a working electrode "b" (formed from one component of the alloy to be investigated, e.g. Al), and an auxiliary polarizing electrode " $\mathrm{c}$ " (Fe). By cathodic polarization relative to " $\mathrm{c}$ ", Ca is deposited at "b" to form an alloy (e.g. Al-Ca), and equally by polarization relative to " $c$ " Ca is deposited at " $a$ " providing a pure Ca reference. The depolarization of the alloy and pure $\mathrm{Ca}$ electrodes, resp. (Ref.81) is then observed as a function of time with respect to the metal/metal oxide reference electrode. Constant emf value steps on the polarization curves define the pure $\mathrm{Ca} / \mathrm{CaF}_{2}$ potential of " $a$ " and those of " $b$ " corresponding to the successive two-phase equilibria of the binary alloy system. Combination of the two sets of observations give activity and partial free energy values of $\mathrm{Ca}$ in each two-phase region, and also the integral values (e.g. Ref.82). A very comprehensive literature survey of studies employing solid electrolytes up to 1988 has been given by Pratt (Ref.8). 


\section{VAPOR PRESSURE METHODS}

The most suitable method for the determination of thermodynamic activities and to a lesser degree enthalpies of mixing at high temperatures (up to temperatures above 2500 $K)$ and over a wide pressure range is the Knudsen effusion technique especially in combination with mass spectrometry. In general partial pressures can be determined by this method between $10^{-5}$ and $10 \mathrm{~Pa}$. By an ion counting system and special baking procedures partial pressures can be determined down to $10^{-7} \mathrm{~Pa}$ (Ref. 83), and the sensitivity can be further improved by a special ion source (Ref. 84, 85). Extension of the range to higher pressures up to $10^{5} \mathrm{~Pa}$ can be obtained by combining the transpiration method with mass spectrometry (Ref.86,88). An overview of effusion methods and associated problems was given in the NBS volumes edited by Hastie (Ref. 87). Several recent reviews of Knudsen effusion methods can be found in literature. Chatilion et al reported on the interactions between Knudsen cells and the systems investigated (Ref, 89) and presented a review of the determination of thermodynamic properties of condensed phases (Ref. 90). Drowart (Ref. 91) surveyed mass spectrometric investigations on gaseous species and thermodynamic properties of condensed phases in equilibrium with the gas phase, sidorov et al (Ref. 92) discussed the application of mass spectrometry to ion-ion, ion-molecule, and molecule-molecule equilibria in high temperature vapors, Hilpert (Ref, 9) reviewed the application of Knudsen effusion mass spectrometry to the chemistry of inorganic vapors, Neckel (Ref. 93) discussed especially the intensity ratio-integration methods as applied to the determination of thermodynamic activities and mixing functions of liquid and solid alloys by Knudsen effusion mass spectrometry, and Tomiska (Ref. 94) surveyed the Knudsen effusion recoil methods.

In all Knudsen methods the most important part is the Knudsen cell which is a cylindrical crucible with a knife-edged or cylindrical orifice $(0,1-1$ mm diameter). The temperatures are measured with an optical pyrometer and /or a thermocouple. Inside a closed cell thermodynamic equilibrium between the condensed sample and its vapor phase is established. In a real cell with an orifice a small fraction of the molecules (atoms) effuses, and it is assumed that the equilibrium in the cell is not disturbed. Effusion through the orifice gives a molecular beam which ideally spreads out in isotropic distribution over a sphere ("cosine law"). The pressure of the escaping molecular beam can be calculated from the equation for steady-state effusion of dilute gases by Knudsen. Vapor pressure measurements based on Knudsen effusion can be performed by the mass-loss technique, by the momentum sensor techniques, or by mass spectrometry. In the mass- loss technique the mass rate of effusion is determined by suspending the Knudsen cell from a micro balance or the effusing species is collected and the amount condensed analyzed by weighing, neutron activation, microprobe or radiochemical counting. The momentum sensor techniques allow the determination of vapor pressures either by impact or recoil momentum sensors. Impact sensors are in general not sufficiently sensitive and the fate of the impinging molecules (whether they condense or revaporize from the target) has to be known. Three recoil momentum sensors are described in literature, the MIKER (microbalance-inverted-Knudseneffusion-recoil), the TORKER (torsion-Knudsen-effusion-recoil), and the PENKER (Pendulum-electronically-balanced-Knudsen-effusion-recoil) technique. The momentum sensor techniques have been discussed in detail by Tomiska (Ref. 94).

The Knudsen effusion mass spectrometry is a well-established method in high temperature chemistry, and it is particularly suitable for the investigation of hightemperature vapors and for the determination of thermodynamic properties of alloys. In this method the effusing molecular beam crosses the electron impact ion source. The ionized vapor beam is analyzed mass spectrometrically, and the partial pressures are computed from the Knudsen cell temperatures and the ion intensities of the vapor species identified.

Different types of mass spectrometers based on different principles for the mass separating system are applied in high temperature chemistry. Single-focusing magnetic sector field or quadrupole mass spectrometers are used in most cases for the analysis of the molecular beam. All single-focusing spectrometers are equipped with a magnetic sector field with an angle of deflection of $60^{\circ}, 90^{\circ}$ or $180^{\circ}$. The magnetic sector field has a direction focusing action. Double-focusing instruments (e.g. Ref. 95, 96) contain in addition to a conventional magnetic sector field an electrostatic sector field and use both direction and velocity focusing. By this principle a high mass resolution can be achieved. Interfering background ion intensities can be avoided which reduce the sensitivity of the instrument for the vapor pressure measurement. However, the sensitivity of the improved single-focusing magnetic type sector field 
instrument (Ref, 84,85 ) at a resolution of $\mathrm{m} / \mathrm{m}=1000$ and of a standard double focusing instrument is roughly comparable. Time-of-flight instruments are based on the measurements of the velocity of ions, and have also been used for the study of vaporization processes because of their rapid mass scan (see e.g. Ref. 97). Using electron impact ionization with a Knudsen cell they have a lower resolution and a lower sensitivity for vapor pressure measurements compared with a magnetic sector instrument. However, since they operate in a discontinuous pulsed mode, and due to their high transmission, they might be employed in systems using photoionization (e.g. Ref. 98).

With a quadrupole mass spectrometer mass separation is achieved by the excitation of ion oscillations generated by an electric radio frequency field. A quadrupole mass filter is sensitive but its sensitivity is mass dependent. They are well suited for investigations in the range up to 200 or 300 amu, Quadrupole mass filters are comparatively low-priced, have a compact form, and the analyzer can be brought very close to the vaporizing surface. After calibration masses can be adjusted with high reproducibility and long-time stability without measuring the ion intensities. A study of the vaporization behavior of chromium silicides at two laboratories (Ref. 99)-one using a single focusing magnetic sector mass spectrometer, the other a quadrupole mass filter-gave very good agreement of the results provided vapor pressures of the pure elements were used to establish instrumental sensitivity, cell walls were in equilibrium with the sample, and care was taken to calibrate and measure the temperature. Hastie and Swingler (Ref. 100) have discussed in detail the advantages of a quadrupole mass filter for studies involving high sample pressures (lower voltages reduce problem of electrical discharges; not as susceptible to voltage leakage due to material condensation an insulators; larger ion currents attainable; use of Faradaycup collector possible which avoid mass discriminating effects of electron multipliers).

Knudsen cells of different design have been described in the literature, the design depending on the particular object of the investigation. Cells are made of tungsten, molybdenum, or graphite, with linings to avoid reactions between sample and cell materials, special "anti-creep" designs to prevent bulk surface flow (creeping), and for the determination of activities multiple cells have been employed (e.g. Ref. 89, $101,102)$. They can be heated by electron bombardment, by radio frequency, by resistance heating, or by heat pipe envelopes which are especially effective in reducing thermal gradients. An effusion experiment is based on several assumptions: 1) The cell is isothermal and the temperature is accurately known. 2)The cell is in thermodynamic equilibrium (temperature gradients cause mass transport effects; lower orifice temperatures may obstruct the hole).3) The cell is assumed to be inert, i.e. the only interactions with the walls are random reflections (grain boundary or surface diffusion, diffusion into or through the wall, bulk surface flow and chemical reactions with the cell are absent). The effect of surface diffusion in and near the orifice has been discussed by Chatillon et al (Ref. 103) and Wahlbeck (Ref. 104). 4) The orifice is ideal (zero thickness) or the geometry is well known and Clausing factors are available. Cylindrical orifices maintain intensity along the orifice axis, thereby making possible a high sensitivity of the system at reduced effusion rate due to the comparatively low transmission probability of such orifices given by their Clausing factor (Ref. 104). 5) Pressures are in the molecular flow region. - Real cells deviate from equilibrium-due to the orifice a pressure gradient is established yet the isotropy condition is assumed. Correction factors for the effects of cell geometry and vaporization coefficients are available. Surface diffusion will enhance the measured pressure, especially with ideal orifices. Bulk surface flow can be reduced by proper cell design, e.g. using single crystal cells, sharp-edged cups, or selecting material that is not wetted by the sample. Tendency towards surface depletion - a problem with solid samples-increases with temperature, and it can be reduced by using a large sample surface and keeping the change in composition small. In Knudsen effusion mass spectrometry the partial pressure $p_{i}$ of a species $i$ is proportional to the current intensity $I_{i}$ and the absolute temperature $T$ and inversely proportional to a factor $S_{i}$ which in turn is proportional to $\sigma_{i}(E)$ the electron impact cross section at the electron energy $E$, to $\gamma_{i}$ the multiplier gain, to $N_{i}$ the relative abundance of the isotope of species $i$. whose current intensity $I$ is measured, and to $C$ the sensitivity factor which includes geometric and electrostatic factors of the Knudsen cell and the ion source. $S_{i}$ can be determined by calibration (e.g. Ref. 105). In alloy thermodynamics one has to determine the activity $a_{i}$ of species $i$ of the condensed phase which in the mass spectrometric method requires the measurement of pi and $\mathrm{pi}_{\mathrm{i}}$, the vapor pressure of the pure component, in two successive experiments. If 
all factors in the two experiments are equal the activity should be obtained by forming the ratio of the ion current intensities $I_{i}$ and $I_{i}$. However, small changes in the experimental setup between different experiments are unavoidable and accurate determinations of activities from successive experiments are therefore not possible. For accurate activity measurements the ion current intensities of the alloy and the pure component have to be determined in a single experiment. This can be accomplished by using dual (e.g. Ref. 102), triple (e.g. Ref. 101), or multiple (e.g. Ref. 89) cells. By correcting for possible differences in the effusion orifices activities can be obtained from the ratio of ion current intensities $I_{i}$ and $I_{i}^{\infty}$, resp. The advantages of multiple cell methods are that activity at a single composition can be obtained, and alloys with significant differences in partial pressures of the components can be investigated. Problems arise from the difficulty in reproducing successive cell positionings, temperature gradients in bigger multiple cells, and possible concentration changes during longer experiments. The triple cell method (Ref. 101) requires isotopically enriched samples; interdiffusion between reference and alloy cells is a possible source of error.

The intensity ratio-integration methods require that both components have measurable and comparable vapor pressures over a wide range of compositions and temperatures. Measurements have to be carried out over concentration ranges, and relations have to be applied which connect the ratio of the partial pressures to a thermodynamic function (e.g. Ref. 106). The special advantage of the intensity ratio-integration method which has been discussed in great detail by Neckel (Ref. 94) is that only a "standard" Knudsen cell is needed. A comprehensive account of the compounds and alloys investigated by Knudsen effusion mass spectrometry since 1979 was given by Hilpert(Ref. 9).

\section{REFERENCES}

1. K.L. Komarek, Z. Metallkd. 64, 325-341, 406-418(1973)

2. K.L. Komarek, Ber.Bunsenges.Phys.Chem. 81, 936-949 (1977)

3. K. L. Komarek, Ber.Bunsenges. Phys.Chem. 87, 709-717 (1983)

4. H. Ipser and K.L. Komarek, Z. Metallkd. 75, 11-22 (1984)

5. K.L.Komarek and H.Ipser, Pure Appl.Chem. 56, 1511-1526 (1984)

6. H. Brodowsky and H.-J. Schaller (eds.) Thermochemistry of Alloys: Recent Developments of Experimental Methods, Kluwer Acad. Publishers, Dordrecht (1989)

7. C.R.A. Catlow (ed.) Advances in Solid-State Chemistry Vol. 1; JAI Press Ltd., London (1989)

8. J.N. Pratt, Metall. Trans. 21A, 1223-1250 (1990)

9. K. Hilpert, Structure and Bonding 73, Springer-Verlag, Berlin, 97-198 (1990)

10. E. Hayer, K.L. Komarek, J.P. Bros and M. Gaune-Escard Z. Metallkd.72,109-115 (1981)

11. F. Grønvold and E.F. Westrum, Jr., J. Chem.Thermodyn. 19, 1183-1198 (1987)

12. F. Grønvold, S. Stølen, E.F. Westrum, Jr. and C.G. Galeas, ibid 19 1305-1324 (1987)

13. J. Rogez and J.Le Coze, Rev. Phys, Appl. 15, 341-351 (1980)

14. O. Kubaschewski and J. Grundmann, Ber,Bunsenges. Phys.Chem, 81 1239-1242 (1977)

15. A. Cezairliyan, High Temp. Sci.13, 117-133 (1980)

16. E.E. Shpilrain, D.N. Kagan and S.N. Ulyanov, High Temp. 19, 882-887 (1981)

17. U. Seydel, H. Bauhof, W. Fucke and H. Wadle, High Temp. -High Press. 11, 35-42 (1979)

18. R. Castanet and C. Bergman, J.Less-Common Met. 68, 119-124 (1979)

19. R. Castanet and C. Bergman, Phys.Chem.Liquids 14, 219-226 (1985)

20. G. Betz and M.G.Frohberg, High Temp. -High Press. 12, 169-178 (1980)

21. G. Betz and M.G. Frohberg, Z. Metallkd, 71, 451-455 (1980)

22. E. Arpaci and M.G. Frohberg, Z. Metallkd.73, 548-551(1982)

23. E. Arpaci and M.G. Frohberg, Z. Metallkd. 75, 614-618 (1984)

24. R. Lin and M.G. Frohberg, Z, Metallkd. 82, 48-52 (1991)

25. R. Lin and M.G. Frohberg, see Ref, 6, 169-176

26. R. Castanet, see Ref. 6 145-168 
27. G. Oehme and B. Predel, Thermochim, Acta 22 267-273 (1978)

28. S. Hassam, M. Gaune-Escard and J.P. Bros, High Temp. Sci, 16, $131-151$ (1983)

29. R. Lück and B. Predel, Z. Metallkd., 76, 684-686 (1985)

30. J.P. Bros, see Ref. 6, 119-143

31. O.J. Kleppa and L. Topor, Thermochim.Acta 139, 291-297 (1989)

32. O.J. Kleppa and W.-G.Jung, High Temp. Sci. 29, 109-123 (1990)

33. W.-G. Jung and 0.J. Kleppa, J.Less-Common Met. 169,85-92 (1991)

34. W. - G. Jung and 0.J. Kleppa, ibid 169, 93-103 (1991)

35. J.C. Gachon, M. Notin and J. Hertz, Thermochim.Acta 48, 155-164 (1981)

36. J.C. Gachon, M. Dirand and J. Hertz, J.Less-Common Met. 85, 1-9 (1982)

37. J.C. Gachon, M. Dirand and J.Hertz, J.Less-Common Met. $92,307-315(1983)$

38. J.C. Gachon, and J. Hertz, Calphad 7, 1-12(1983)

39. J.C. Gachon, J. Charles and J. Hertz, Calphad 9, 29-34(1985)

40. J. Hertz, see Ref. 6 307-328

41. E. Arpaci and M.G. Frohberg, Z. Metallkd. 76, 440-444 (1985)

42. P. Gerdanian, see Ref. 7 ,

43. L.B. Ticknor and M.B. Bever, J. Met. 4, 941-945 (1952)

44. H. Said and R. Castanet, J. Less-Common Met. 68,_213-221 (1979)

45. W. Vogelbein, M. Ellner and B. Predel, Thermochim, Acta 44, 141-149 (1981)

46. L. Topor and 0.J. Kleppa J.Chem. Thermodyn. 16 993-1002 (1984)

47. L. Topor and 0.J. Kleppa, J.Chem.Thermodyn. 17, 1003-1016 (1985)

48. A.W. Bryant and J.N. Pratt, in Metallurgical Chemistry Symp. Brunel Univ. - NPL, O. Kubaschewski (ed.), paper 1.2, HMSO, London (1972)

49. M. Notin, J.C. Gachon and J. Hertz, J. Chem. Thermodyn. 14, $425-434$ (1982)

50. H. Said and R. Castanet, High Temp. -High Press. 10 681-692 (1978)

51. C. Bergman and K.L. Komarek, Calphad 9, 1-14 (1985)

52. 2. Moser, in: Calculation of Phase Diagrams and Thermochemistry of Alloy Phases, Y.A. Chang and J.F. Smith (eds.), AIME, Warrendale, Pa., 242-274 (1979)

53. C. Wagner and A. Werner, J. Electrochem. Soc. 110, 326-333 (1963)

54. K. Okajima and H. Sakao, J. Japan Inst. Metals 31, 537-541 (1967)

55. K. Okajima and H. Sakao, Trans. JIM 9, 47-53 (1968)

56. K. Okajima, Mem. Fac. Eng. Nagoya Univ. 41, 209-279(1990)

57. S. Geller (ed.)., Solid Electrolytes, Top. Appl. Phys. 21, Springer Verlag, Berlin, (1977)

58. E.C. Subbarao (ed.). Solid Electrolytes and Their Applications, Plenum Publ. Corp., New York (1980).

58a.A.J. Burggraaf,B.A. Boukamp, I.C.Vinke and K.J. de Vries, see Ref.7,

59. H. -J. Schaller, see Ref.6, $329-358$

60. J.J. Egan, see Ref. 6, 371-398

61. A.M. Anthony, J.F. Baumard and J. Corish, J. Pure Appl.Chem. 56 1069-1094 (1984)

62. H. Schmalzried, Z.phys.Chem. NF 38, 87-102(1963)

63. H. Schmalzried, Z.Elektrochem. 66, 572-576(1962)

64. H. Schmalzried, Z.Phys.Chem. 25, 178-192 (1960)

65. J.W. Patterson, J.Electrochem.Soc. 118, 1033-1039(1971)

66. C. Wagner, J.Electrochem.Soc, 115, 933-935 (1968)

67. J.W. Hinze and J.W. Patterson, J.Electrochem.Soc. 120, 96-99 (1973)

68. J.Delcet, R.J.Heus and J.J.Egan, J.Electrochem.Soc: 125 755-58(1978)

69. V.A. Levitskii, J.Solid State Chem. 25, 9-22 (1978)

70. H. Kleykamp. Ber. Bunsenges. Phys.Chem. 87 777-781 (1983)

71. M.L. Saboungi, S.J. Herron and R. Kumar, Ber.Bunsenges. Phys. Chem. 89, 375-380(1985)

72. F.E. Neale and N.E. Cusack, Z. phys. Chem.NF, 156,551-556(1988)

73. J.T. Kummer, Prog.Solid State Chem.7, 141-175(1972)

74. G.C. Farrington and B.Dunn, Solid State Ionics 7,267-281(1982)

75. G.C. Farrington, B.Dunn and J.O. Thomas, Appl.Phys.A32, $159-161$ (1983) 
76. C. Wagner, Prog. Solid State Chm. 6, 1-15 (1977)

77. A. Nakamura and T. Fujino, J. Nucl.Mater. 149, 80-100(1987)

78. M.L. Saboungi and T.P. Corbin, J.Phys.F 14, 13-21 (1984)

79. J.J. Egan and W. Freyland, Ber. Bunsenges. Phys. Chem. 89, 381 - 384 (1985)

80. G. Lefebvre, M. Notin, J.P. Hilger and J. Hertz, J. Solid State Chem, 28, 97-108 (1979)

81. M. Notin and J. Hertz, Calphad 6, 49-56 (1982)

82. M. Notin, J.C. Gachon and J. Hertz, J.Less-Common Met. 85 , 205-212 (1982)

83. K. Hilpert in: Advances in Mass Spectrometry 7A, N.R. Daly (ed.), Heyden, London, 584-587 (1978)

84. K. Hilpert, Ber. Bunsenges. Phys.Chem. 88, 260-262 (1984)

85. K. Hilpert and K. Ruthardt, Ber.Bunsenges, Phys. Chem. 91, 724-731 (1987)

86. J.W. Hastie Pure Appl.Chem. 56, 1583-1600 (1984)

87. J.W. Hastie (ed.), Characterization of High Temperature Vapors and Gases, NBS Spec.Publ. 561 (1979)

88. D.W. Bonnell and J.W. Hastie, see Ref. 87, 357-409

89. C. Chatillon, M.Allibert and A. Pattoret, see Ref, 87, 181-210

90. C. Chatillon, A. Pattoret and J. Drowart, High Temp.-High Press. 7, 119-148 (1975)

91. J. Drowart, in: Advances in Mass Spectrometry 1985, A, J.F.J. Todd (ed.) J. Wiley, New York, 195-214 (1986)

92. L.N. Sidorov, L.V. Zhuravleva and I.D. Sorokin, Mass Spectr. Reviews 5, 73-97 (1986)

93. A. Neckel, see Ref, 6, 221-246

94. J. Tomiska, see Ref. 6, 247-260

95. R.H. Moore, D. Robinson and B.B. Argent, J.Phys.E 8,641-648 (1975)

96. G. Riekert, P. Lamparter and S. Steeb, Z.Naturforsch. A 36 , 447-453 (1981)

97. L. Timberg, J.M. Toguri and T. Azakani, Metall.Trans. 12B, 275-279 (1981)

98. J. Grotemeyer and E.W. Schlag, Angew. Chem. 100, $461-474$ (1988)

99 . G.A. Murray, R.J. Kematick, C.E. Myers and M.A. Frisch, High Temp.Sci, 26, 415-425 (1990)

100. J.W. Hastie and D.L. Swingler, High Temp. Sci. 1, 46-57 (1969)

101. J. V. Hackworth, M. Hoch and H.L. Geyel, Met.Trans.2, $1799-1805$ (1971)

102. M.J. Stickney, M.S. Chandrasekharaiah and K.A.Gingerich, High Temp.Sci.26, 187-195 (1990)

103. C. Chatillon, M. Allibert and A. Pattoret, High Temp. Sci.8, 233-255 (1976)

104. P.G. Wahlbeck, High Temp. Sci. 21, $189-232$ (1986)

105. R.T. Grimley in: The Characterization of High Temperature Vapors, J.L. Margrave (ed.), J.Wiley, New York, 195 - 243 (1967)

106. A. Neckel and S. Wagner, Ber.Bunsenges. Phys.Chem. 73, $210-217$ (1969) 